\title{
Mapping quantitative resistance to septoria tritici blotch in spelt wheat
}

\author{
Maria Rosa Simon • Elena K. Khlestkina • \\ Nadia S. Castillo • Andreas Börner
}

Accepted: 26 May 2010 / Published online: 26 August 2010

(C) KNPV 2010

\begin{abstract}
The foliar wheat disease septoria tritici blotch can cause significant yield losses. A source of resistance has been mapped on chromosome 7D of spelt wheat, Triticum aestivum L. subsp. spelta (L.) Thell. The microsatellite-based genetic map was constructed from a set of 87 single-chromosome recombinant doubledhaploid lines bred from the cross between the landrace
\end{abstract}

Maria Rosa Simon, Elena K. Khlestkina and Nadia S. Castillo contributed equally.

Electronic supplementary material The online version of this article (doi:10.1007/s10658-010-9640-y) contains

supplementary material, which is available to authorized users.

M. R. Simon $(\bowtie) \cdot$ N. S. Castillo

Facultad de Ciencias Agrarias y Forestales,

Universidad Nacional de La Plata,

60 y 119 . CC 31 ,

1900 La Plata, Argentina

e-mail: mrsimon@agro.unlp.edu.ar

E. K. Khlestkina

Institute of Cytology and Genetics, SB RAS,

Novosibirsk 630090, Russia

N. S. Castillo

CONICET,

Consejo Nacional de Investigaciones Científicas,

Buenos Aires, Argentina

A. Börner

Leibniz Institute of Plant Genetics

and Crop Plant Research (IPK),

Corrensstr. 3,

06466 Gatersleben, Germany
'Chinese Spring' and a 'Chinese Spring'-based line carrying chromosome 7D from spelt wheat. Two regions of the chromosome were associated with isolate-specific QTL expressed one at the seedling and another at the adult plant stage. The seedling resistance locus QStb.ipk-7D1 was found in the centromeric region of chromosome 7D, which corresponds to the location of the major resistance genes Stb4 originating from bread wheat cultivar 'Tadinia' and Stb5 originating from Triticum tauschii. The adult resistance locus QStb.ipk-7D2 was found on the short arm of chromosome 7D in a similar position to the locus $\operatorname{Lr} 34 /$ Yr 18 known to be effective against multiple pathogens. Composite interval mapping confirmed QStb.ipk-7D1 and QStb.ipk-7D2 to be two distinct loci.

Keywords Mycosphaerella graminicola.

QTL mapping $\cdot$ Septoria tritici .

Triticum aestivum L. subsp. spelta (L.) Thell

\section{Introduction}

The foliar wheat disease septoria tritici blotch is caused by Mycosphaerella graminicola (Fückel) Schröter in Cohn (anamorph Septoria tritici Rob ex Desm.). Severe levels of infection can lead to significant yield losses (Hardwick et al. 2001). Resistant cultivars provide an effective, economical and environmentally friendly approach to control septoria tritici blotch epidemics, but until recently 
little was known about the genetics of resistance to the disease.

Both qualitative and quantitative resistance have been identified in wheat germplasm. The former typically gives near complete resistance, is isolate specific and is simply inherited (Brading et al. 2002). In contrast, while the latter gives only partial, although often more durable protection, it is not generally isolate specific and is mainly under polygenic control (Jlibene et al. 1994; Simón and Cordo 1998). The 13 major resistance genes mapped to date in bread wheat (Triticum aestivum L.) are Stb1-Stb12 and Stb15 (McIntosh et al. 2008). A number of quantitative trait loci (QTL) has also been identified (McIntosh et al. 2008). Raman et al. (2009) have identified recently a major gene conferring seedling resistance on wheat chromosome arm 1BS, which is, probably, allelic to Stb11.

Some other Triticum species have also been identified carrying resistance. Triticum monococcum, T. piramidale, T. dicoccoides, T. dicoccum, T. polonicum, T. carthlicum and T. macha have been reported to carry resistance (Arraiano et al. 2001a; Simón et al. 2005b; Singh et al. 2008). Arraiano et al. (2001b) identified the Stb5 gene on the short arm of chromosome 7D of a synthetic hexaploid wheat. In addition resistance was found in 24 T. monoccocum accessions and a single genetic locus, TmStbl, was linked to the microsatellite locus Xbarc174 on chromosome $7 \mathrm{~A}^{\mathrm{m}}$ (Jing et al. 2008). Spelt wheat (Triticum aestivum L. subsp. spelta (L.) Thell) represents a source of genetic resistance to various diseases, including stem rust (McVey and Leonard 1990), yellow rust (Kema 1992), septoria tritici blotch (Simón et al. 2005b; Singh et al. 2008), and head blight (Wiwart et al. 2004). Simón et al. (2005b) identified substitution lines of chromosome 7D of $T$. aestivum subsp. spelta that carried resistance to Mycosphaerella graminicola. However, the resistance factor has not been identified. Chromosomes 7B and 7D also carry factors on their short arms which interact to influence resistance to Puccinia striiformis (Pink and Law 2009)

A complication in identifying genetic resistance to septoria tritici blotch is a possible interaction between resistance and flowering time, with increased disease severity being associated with earlier flowering cultivars (Van Beuningen and Kohli 1990). Although those traits may not be genetically associated and the association instead may be due to epidemiological factors (Simón et al. 2005a), information is lacking about the position of resistance genes and late-flowering genes in the same germplasm using molecular marker-based approaches to confirm the absence of genetic associations. Association of resistance to $S$. tritici with chromosome 7D of T. aestivum subsp. spelta (Simón et al. 2005b) may suggest a possible linkage to some locus controlling this trait, because homoeologous group 7 chromosomes are known to carry several loci controlling this trait (McIntosh et al. 2008).

The aim of this research was to genetically map the position of the resistance against septoria tritici blotch on chromosome 7D using a cross between 'Chinese Spring' ('CS') and the chromosome substitution line 'CS' ( $T$. aestivum subsp. spelta 7D) and to test whether this effect was associated with variation for flowering time.

\section{Materials and methods}

Parental screening with several isolates

The landrace 'Chinese Spring' ('CS') and the singlechromosome substitution line ' $\mathrm{CS}$ ' $(T$. aestivum subsp. spelta 7D) (in which ' $\mathrm{CS}$ ' chromosome 7D has been replaced by $T$. aestivum subsp. spelta 7D in the genetic background of 'CS') ('CS' (T.a.s.7D)) differed in their reaction to $M$. graminicola infection with one isolate (Simón et al. 2005b). The two lines were tested with a set of Argentinean pathogen isolates in two environments (one in the field and the other in pots outside) in 2004 using a factorial randomized block design with three replications. The field experiment was performed at the Estación Experimental J. Hirschhorn, and the pot experiment at the Universidad Nacional de La Plata. Eight to ten seeds per line were sown into 10-1 pots or in each row in the field. The plants were watered regularly (every 2-3 days), and provided at sowing with $50 \mathrm{~kg} \mathrm{ha}^{-1}$ of $\mathrm{N}$ as urea and $50 \mathrm{~kg} \mathrm{ha}^{-1}$ of ammonium diphosphate, and at tillering with $50 \mathrm{~kg} \mathrm{ha}^{-1}$ of urea.

The ten fungal isolates (FALP 6792, 1493, 0103, 0203, 0303, 0403, 0503, 0603, 0703 and 0803) were selected according to their different origins in the Argentinean wheat region. The isolates were kept in silica gel and were transferred to malt extract agar for 56 days before carrying out the experiments. Inoculum was prepared by suspending conidia scraped from sporulating colonies in deionized water at a concentra- 
tion of $5 \times 10^{6}$ spores $\mathrm{ml}^{-1}$. Tween $20(0.5 \mathrm{ml}$ per litre $)$ was added as a surfactant. Plants were inoculated at both the seedling (two-leaf stage, GS 12, Zadoks et al. 1974) and adult stages (at tillering, GS 23, Zadoks et al. 1974). For the experiment in pots, plants were covered with a transparent plastic wrap for $48 \mathrm{~h}$ immediately after inoculation to maintain the level of humidity. For the experiment in the field, plants were kept moist by spraying with water for 15 min every $2 \mathrm{~h}$ during three days.

To estimate seedling resistance, the first leaf of each plant was visually assessed for necrosis and pycnidial coverage at 28 to 30 days after inoculation . For the evaluation of adult-stage resistance, plants were scored for necrosis and pycnidial coverage at 30 days after flag leaf emergence (GS 82). Analysis of variance was performed on necrosis and pycnidial coverage on the first leaf of seedlings and on the flag leaf of plants at GS 82. Factors were the environments (years), the isolates and the lines.

Mapping population and resistance analysis

A random set of 87 single-chromosome recombinant doubled-haploid (SCRDH) lines was derived by crossing the $\mathrm{F}_{1}$ ' $\mathrm{CS}$ ' (T. a.e.7D) / 'CS' with maize,

Table 1 Means of necrosis and pycnidial coverage (\%) in seedlings of Chinese Spring (CS) and CS (T. aestivum subsp. spelta 7D) tested with 10 isolates of Mycosphaerella graminicola

\begin{tabular}{lllllr}
\hline \multirow{2}{*}{ Isolates } & \multirow{2}{*}{$\mathrm{CS}^{\mathrm{a}}$} & & & \multicolumn{2}{c}{$\mathrm{CS}(7 \mathrm{D})^{\mathrm{b}}$} \\
\cline { 2 - 3 } \cline { 5 - 6 } & Necrosis & Pycnidia & & Necrosis & Pycnidia \\
\hline 6792 & 40.6 & 10.0 & & 28.6 & 8.9 \\
1493 & 40.0 & 12.5 & & 32.1 & 13.5 \\
0103 & 58.3 & 33.3 & & 20.7 & 13.2 \\
0203 & 57.5 & 35.0 & & 67.9 & 37.5 \\
0303 & 70.8 & 42.5 & & 67.5 & 43.6 \\
0403 & 62.9 & 47.1 & & 37.5 & 20.0 \\
0503 & 25.0 & 24.2 & & 19.0 & 19.2 \\
0603 & 35.0 & 25.0 & & 40.0 & 30.0 \\
0703 & 51.2 & 36.2 & & 61.2 & 40.0 \\
0803 & 77.5 & 35.0 & & 78.0 & 40.0 \\
\hline
\end{tabular}

${ }^{\mathrm{a}}$ Chinese Spring

${ }^{\mathrm{b}}$ Chinese Spring (T. aestivum susbsp. spelta 7D)

LSD for the interaction isolate by line necrosis $=10.1$; LSD for the interaction isolate by line pycnidial coverage $=8.3$
Table 2 Means of necrosis and pycnidial coverage (\%) in adult stage (GS 82) for Chinese Spring (CS) and CS (T. aestivum subsp. spelta 7D) tested with 10 isolates of Mycosphaerella graminicola

\begin{tabular}{llllll}
\hline Isolates & \multicolumn{2}{l}{$\mathrm{CS}^{\mathrm{a}}$} & & & \multicolumn{2}{l}{$\mathrm{CS}(7 \mathrm{D})^{\mathrm{b}}$} \\
\cline { 2 - 3 } \cline { 5 - 6 } & Necrosis & Pycnidia & & Necrosis & Pycnidia \\
\hline 6792 & 38.6 & 25.1 & & 27.5 & 22.1 \\
1493 & 40.2 & 31.0 & & 35.1 & 23.7 \\
0103 & 35.7 & 30.2 & & 15.0 & 10.2 \\
0203 & 54.8 & 35.3 & & 45.4 & 29.9 \\
0303 & 48.6 & 37.8 & & 50.5 & 31.8 \\
0403 & 62.0 & 46.6 & & 55.1 & 40.9 \\
0503 & 46.2 & 36.4 & & 51.6 & 35.0 \\
0603 & 38.3 & 32.3 & & 36.0 & 27.6 \\
0703 & 57.7 & 40.8 & & 52.4 & 34.5 \\
0803 & 52.5 & 39.6 & 60.2 & 34.2 \\
\hline
\end{tabular}

${ }^{\mathrm{a}}$ Chinese Spring

${ }^{\mathrm{b}}$ Chinese Spring (T. aestivum susbsp. spelta 7D)

LSD for the interaction isolate by line necrosis $=12.2$; LSD for the interaction isolate by line pycnidial coverage $=7.5$

and treating the progeny with colchicine, following established methods (Laurie and Bennett 1988). The SCRDH lines were sown in pots placed outside along with both parental lines at the La Plata National University in 2005, 2006 and 2007.

Inoculation and evaluation were performed at both seedling and adult stages, using the same procedures as in the screening experiment. On the basis of a differential reaction between the parental lines, pathogen isolate FALP 0103 was selected to inoculate the mapping population at the seedling stage, using the same spore concentration as for the screening experiment. During the period between the inoculation and the evaluation of disease reaction, the mean temperature in each of the growing seasons was $11.7^{\circ} \mathrm{C}, 12.7^{\circ} \mathrm{C}$ and $7.3^{\circ} \mathrm{C}$, and the relative humidity was $90.0 \%, 78.0 \%$ and $74.4 \%$. To estimate adult-plant resistance, percentage necrosis and pycnidial coverage on the flag leaf was recorded 30-35 days after flowering (GS 82), except in 2005 when only necrosis was scored. The mean temperature and relative humidity between inoculation and evaluation were $15.3^{\circ} \mathrm{C}, 16.5^{\circ} \mathrm{C}$ and $13.3^{\circ} \mathrm{C}$ and $66 \%, 67.0 \%$ and $70.3 \%$ for 2005, 2006 and 2007 respectively. The flowering dates of all lines were recorded when $50 \%$ of plants within a line reached anthesis. The amount of rainfall in the three years was 
153, 247 and $272 \mathrm{~mm}$, respectively, for the whole growing period. A linear regression of the number of days to flowering against percentage necrosis or pycnidial coverage was not significant, so no correction to the data was applied.

Analysis of variance was performed on necrosis and pycnidial coverage on the first leaf of seedlings and on the flag leaf of plants at GS 82. Factors were the environments (years) and the lines. Means were compared by LSD test $(P=0.05)$. Correlation between necrosis and pycnidial coverage for each trait was also tested. Significant correlation between percentage necrosis and pycnidial coverage was observed, therefore only one of the two subsets of the scoring data (percentage necrosis) was used for QTL analysis. The results obtained during different years and replicates were combined into one residual mean percentage necrosis score per line. This was performed separately for seedling and adult-plant resistance scores. Then the two datasets were subjected to QTL analysis.
Fig. 1 Histograms of disease severity means over three years of 87 double-haploid lines derived from the cross of ' $\mathrm{CS}$ ' (T. aestivum subsp. spelta 7D) by 'CS' inoculated with Mycosphaerella graminicola isolate a. Necrosis in seedlings. b. Pycnidial coverage in seedlings. c. Necrosis in flag leaves
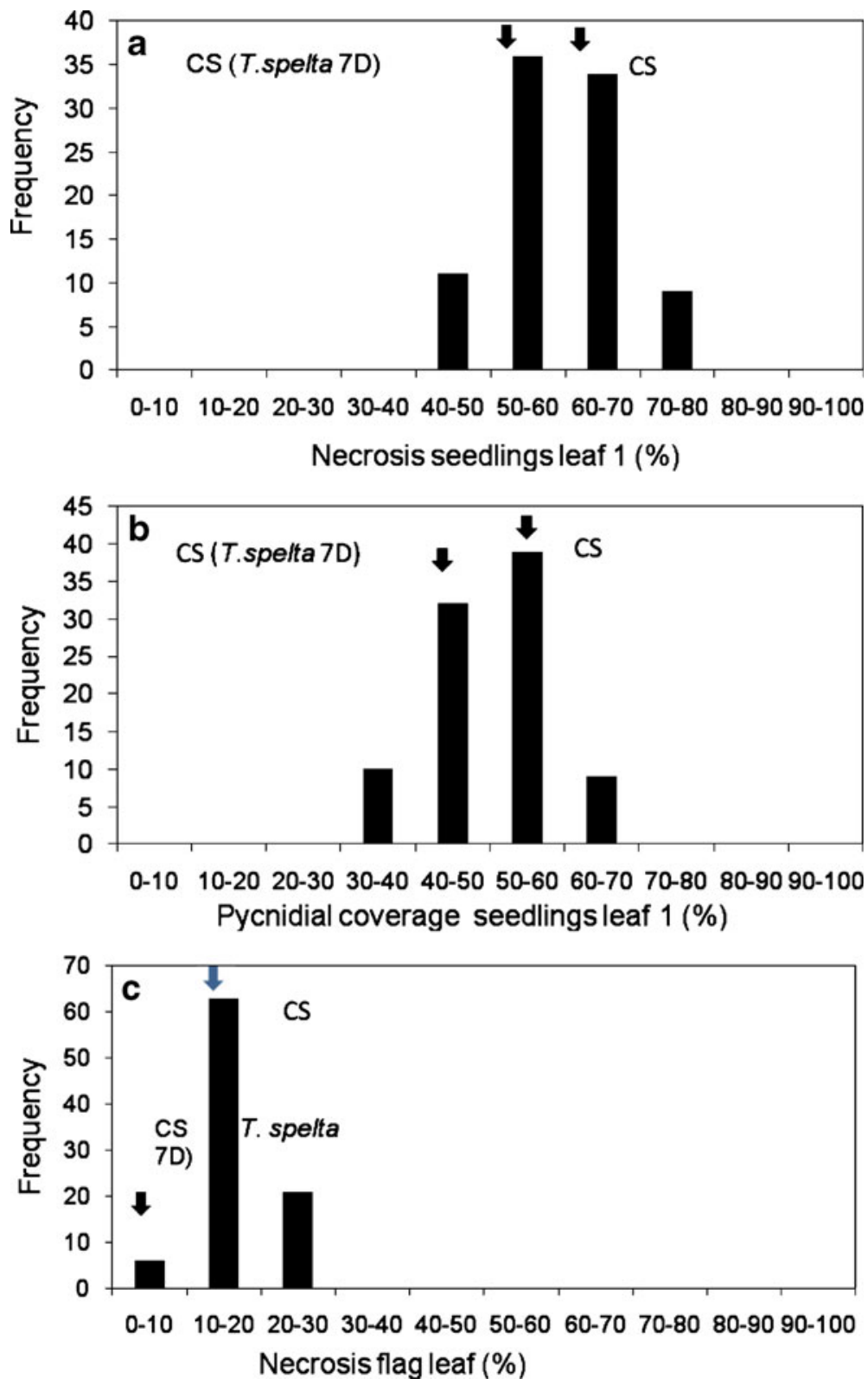
Microsatellite genotyping and QTL analysis

Genomic DNA was extracted following the procedure of Plaschke et al. (1995), and used to assign allelic status at a set of $49 \mathrm{GWM}$ (Gatersleben wheat microsatellite) loci mapped to chromosome 7D. Genotyping methodologies are described elsewhere (Röder et al. 1998). A genetic map of chromosome 7D was constructed with MAPMAKER v2.0 software (Lander et al. 1987). The QTL analysis was carried out using QTX (Manly et al. 2001). QTX expresses the quality of a QTL assignment in the form of a likelihood ratio statistic (LRS). Experiment-wise threshold values were calculated by performing 1000 permutations of the phenotypic data. To control for linked QTL, composite interval mapping was performed using the option provided by QTX, which reduces effects of background QTL.

\section{Results}

Parental screening with several isolates

There were significant differences for necrosis and pycnidial coverage between isolates, lines and for the interaction isolates by lines. Isolate FALP 0103 was selected on the basis of the greatest differential reaction severity between the parental lines in seedlings and the adult stage. $T$.aestivum subsp. spelta $7 D$ also showed some level of resistance in seedlings to isolate FALP 6792 and FALP 0403, whereas both parents showed similar resistance scores to the other isolates (Tables 1 and 2). Thus, on the basis of a differential reaction between the parental lines, pathogen isolate FALP 0103 was selected to inoculate the lines.

Mapping population: resistance test

The ANOVA showed significant differences between environments and SCRDH lines for necrosis and pycnidial coverage at the seedling and adult plant stage. The interaction environment by line was not significant in any case (data not shown). Average data distribution over the three years is shown in Fig. 1. In seedlings there was a resistant:susceptible segregation ratio of 1:1. For necrosis at the flag-leaf stage most of the lines were susceptible and there was a transgressive segregation; 22 were more susceptible than the susceptible parent (Fig. 1).
Mapping population: genotyping and QTL analysis

Of the 49 microsatellite loci tested, 16 were informative for the contrast between 'CS' and 'CS' (T.a.s.7D), and the allelic status of the SCRDH lines at these loci provided the basis for the genetic map of chromosome 7D (Fig. 2). The interval mapping analysis performed using seedling and adult-plant percentage necrosis

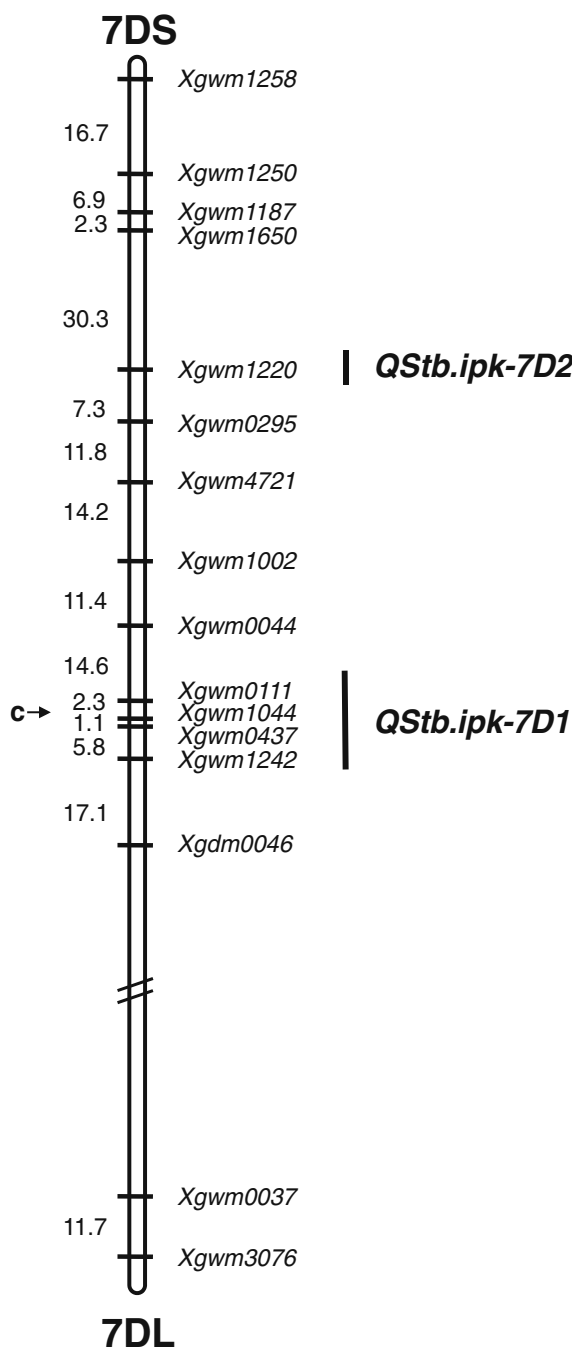

Fig. 2 The genetic map of chromosome 7D constructed from a set of single-chromosome recombinant doubled-haploid lines bred from the cross ' $\mathrm{CS}$ ' (T. aestivum subsp. spelta 7D) by 'CS'. Genetic distances are given in centimorgans (cM); 7DS = short arm; 7DL $=$ long arm; $\mathrm{c}=$ centromeric region. Locations of septoria tritici blotch QTL are indicated to the right. QStb. $i p k-7 D 1$ is a locus for the seedling and QStb.ipk-7D2 for the adult-plant stages of resistance. The centromere is indicated according Khlestkina et al. (2009). Double diagonal slashes indicate missing linkage 
scores (Fig. 3) suggested the presence of the seedling disease-resistance locus in the centromeric region linked to Xgwm0111 (Figs. 2 and 3a), while the adult-plant resistance locus was detected on the short arm in the region of Xgwm1220 (Figs. 2 and 3b). These loci were designated QStb.ipk-7D1 and QStb.ipk-7D2, respectively. Although the two parental lines of the mapping population 'CS' (T.a.s.7D) displayed higher resistance in comparison with ' $\mathrm{CS}$ ' in both seedling and adultplant stages, the additive regression coefficient suggested that 'CS' (T.a.s.7D) conferred the susceptible allele of the seedling resistance locus QStb.ipk-7D1 (Fig. 3a) and the resistant allele of the locus QStb.ipk-7D2 detected using adult-plant resistance scores (Fig. 3b).

Because two linked QTL had been detected, we applied composite interval mapping to reduce effects of such QTL to each other. We performed composite mapping for the seedling resistance trait using adultplant resistance for the trait variances (Supplementary Fig. 1a) and did the same for the adult-plant resistance trait using vice versa the seedling resistance background (Supplementary Fig. 1b). The results obtained for composite interval mapping (Supplementary Fig. 1) were very similar to those derived from interval mapping analysis, confirming existence of two linked resistance QTL on chromosome 7D. Thus, the two distinct loci QStb.ipk-7D1 and QStb.ipk-7D2 confer the resistance in seedlings and adult plants.

Interval mapping analysis of flowering time did not reveal significant LRS values and no measurable correlation between flowering time and seedling or adult-plant resistance was observed, suggesting that the QTL observed for resistance are not associated with variation for flowering time. This was also confirmed by composite interval mapping of the seedling and adultplant resistances, performed using flowering time for trait variances (Supplementary Fig. 2).

\section{Discussion}

In this paper, we describe two loci on wheat chromosome 7D conferring resistance to septoria tritici blotch. Interestingly, the locus conferring adult-plant resistance, QStb.ipk-7D2, maps in the region of microsatellite locus Xgwm1220 where known adult-plant disease resistance locus $L r 34 / Y r 18$, effective against multiple pathogens such as leaf rust, stripe rust, and powdery mildew, is located (Krattinger et al. 2009; Spielmeyer et al. 2008,). It has been shown that the LR34 protein
Fig. 3 Interval mapping of the seedling (a) and adult plant stage (b) resistances. LRS: likelihood ratio statistic; AE: additive effect. "Significant" and "highly significant": LRS threshold lines

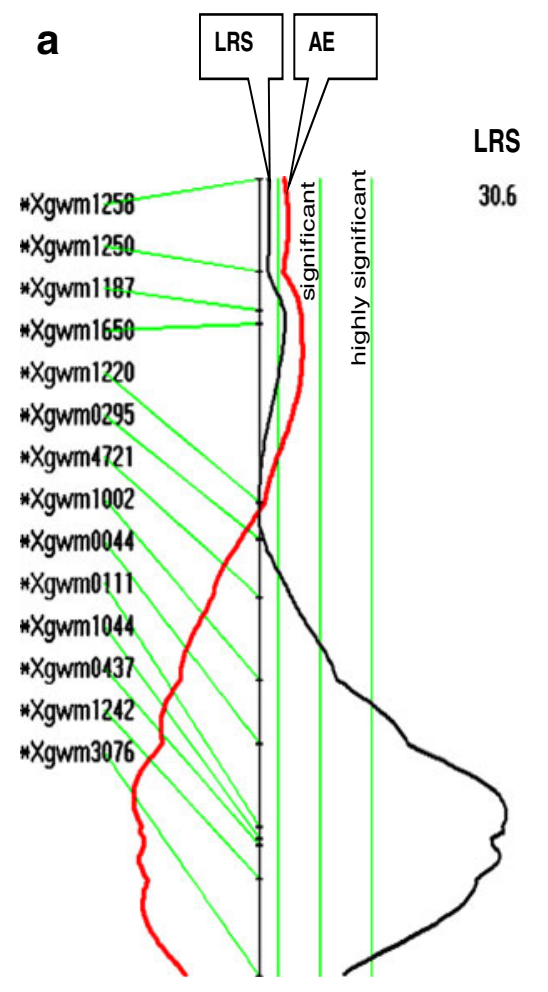


resembles adenosine triphosphate-binding cassette transporters of the pleiotropic drug resistance subfamily (Krattinger et al. 2009). 'CS' carries the Lr34 resistance allele (Dyck 1991). Nevertheless, in our study, the 'CS' parent conferred an allele for susceptibility to septoria tritici blotch in the adult stage. A similar observation was made for $L r 34$ and stem rust; $L r 34$ in 'CS' does not confer resistance to stem rust, while in 'Thatcher' it does (McIntosh et al. 2008). Spielmeyer et al. (2008) proposed that Lr34 interacts with unlinked gene(s) in the 'Thatcher' background resulting in enhanced stem rust resistance in adult plants. Probably, the Lr34 allele of spelt wheat interacts with one or more unlinked genes in the 'CS' background, to enhance septoria tritici blotch resistance in comparison with the combination of the genes in 'CS'. To elucidate this, it will be of interest to investigate in the future how adult-plant septoria tritici blotch resistance in 'CS' (T.a.s.7D) and the 'CS'/“CS' (T.a.s.7D) population correlates with resistance/susceptibility to leaf rust, stripe rust and powdery mildew.

The map position of the locus conferring seedling resistance, QStb.ipk-7D1, also coincides with locations of the known genes: Stb4 (Adhikari et al. 2004), Stb5 (Arraiano et al. 2001b), Dn1, Dn2, Dn5, Dn6, and Dnx (the $D n$ genes confer resistance to Russian wheat aphid; Liu et al. 2001, 2002). This may be either a resistance gene cluster or a locus similar to $\operatorname{Lr} 34 / \mathrm{Yr} 18$ conferring resistance to multiple pathogens. Whether QStb.ipk-7D1 is allelic to the major genes Stb4 and/or $S t b 5$ remains unclear.

The unexpected result of the QTL analysis that 'CS' (T.a.s.7D) confers the susceptible allele of the locus QStb.ipk-7D1 suggests occurrence of a background effect. A similar effect was observed during QTL analysis performed for other traits (Pshenichnikova et al. 2008). Although a single-chromosome substitution line usually receives up to eight backcrosses in the course of its development, this may not be sufficient to fully reconstitute the recipient genetic background (Khlestkina et al. 2010). Thus, the use of the singlechromosome substitution line in the current analysis cannot completely rule out the possibility of a background effect from other chromosomes originating from the donor parent ( $T$. aestivum subsp. spelta). Further chromosomes contributing to resistance of $T$. aestivum subsp. spelta are 2D, 5A, 5D, 6B and 6D (Simón et al. 2005b). Thus, use of the $T$. aestivum subsp. spelta QStb.ipk-7D1 allele as a new source of seedling resistance may be limited to combinations with other $T$. aestivum subsp. spelta resistance loci. Unlike this, the resistance allele at locus QStb.ipk-7D2 is conferred by the 'CS' (T.a.s.7D) parent, suggesting that it can be used as a new source of adult-plant resistance to septoria tritici blotch.

The septoria tritici blotch resistance mapped in the current study appears to be isolate specific since the $T$. aestivum subsp. spelta accession used to create the 'CS' (T.a.s. 7D) line has a good level of resistance to M. graminicola isolate FALP 0103 in seedling and adult stages, some resistance to FALP 9267 in seedlings, but no resistance to the other eight isolates tested here. Stb5, originating from Triticum tauschii, is known to be resistant to IPO 94269 (Arraiano et al. 2001b) and to two Argentinean isolates (Simón et al. 2007). Stb4, originating from bread wheat cultivar 'Tadinia' and conferring resistance at both seedling and adult stages, was effective in California for more than 15 years up to the end of the 1990s (Jackson et al. 2000) but then broke down rapidly.

Overall, resistance to $M$. graminicola can be expressed at either or both the seedling and adult stages. Although there are cultivars with specific resistance available to individual isolates at both stages, others only carry resistance at one stage (Kema and van Silfhout 1997). Cultivars with a reasonable level of quantitative resistance at both stages are available, while others showed resistance in seedlings but were fully susceptible at the adult stage, or vice versa (Simón et al. 2005a). Similarly, some resistance QTL which are growth-stage specific have been identified (McIntosh et al. 2008).

\section{References}

Adhikari, T. B., Cavaletto, J., Dubcovsky, J., Gieco, J. O., Schlatter, A. R., \& Goodwin, S. B. (2004). Molecular mapping of the Stb4 gene for resistance to septoria tritici blotch in wheat. Phytopathology, 94, 1198-1206.

Arraiano, L. S., Brading, P. A., \& Brown, J. K. M. (2001). A detached seedling leaf technique to study resistance to Mycosphaerella graminicola (anamorph Septoria tritici) in wheat. Plant Pathology, 50, 339-346.

Arraiano, L. S., Worland, A. J., Ellerbrook, C., \& Brown, J. K. M. (2001). Chromosomal location of a gene for resistance to Septoria tritici blotch (Mycosphaerella graminicola) in the hexaploid wheat 'Synthetic 6x'. Theoretical and Applied Genetics, 103, 758-764.

Brading, P. A., Verstappen, E. C. P., Kema, G. H. J., \& Brown, J. K. M. (2002). A gene-for-gene relationship between 
wheat and Mycosphaerella graminicola, the Septoria tritici blotch pathogen. Phytopathology, 92, 439-445.

Dyck, P. L. (1991). Genetics of adult plant leaf rust resistance in Chinese Spring and 'Sturdy' wheats. Crop Science, 24, 309-311.

Hardwick, N. V., Jones, D. R., \& Slough, J. E. (2001). Factors affecting diseases of winter wheat in England and Wales, 1989-98. Plant Pathology, 50, 453-462.

Jackson, L. F., Dubcovsky, J., Gallagher, L. W., Wennig, R. L., Heaton, J., Vogt, H., et al. (2000). Regional barley and common and durum wheat performance tests in California. Agronomy Progress Report, 272, 1-56.

Jing, H. C., Lovell, D., Gutteridge, R., Jenk, D., Kornyukhin, D., Mitrofanova, O. P., et al. (2008). Phenotypic and genetic analysis of the Triticum monococcum-Mycosphaerella graminicola interaction. New Phytologist, 179, 1121-1132.

Jlibene, M., Gustafson, J. P., \& Rajaram, S. (1994). Inheritance of resistance to Mycosphaerella graminicola in hexaploid wheat. Plant Breeding, 112, 301-310.

Kema, G. H. J. (1992). Resistance in spelt wheat to yellow rust. I. Formal analysis and variation for gliadins patterns. Euphytica, 63, 207-217.

Kema, G. H. J., \& Van Silfhout, C. H. (1997). Genetic variation for virulence and resistance in the wheat-Mycosphaerella graminicola pathosystem. III. Comparative seedling and adult plant experiments. Phytopathology, 87, 266-272.

Khlestkina, E. K., Pshenichnikova, T. A., Röder, M. S., \& Börner, A. (2009). Clustering anthocyanin pigmentation genes in wheat group 7 chromosomes. Cereal Research Communications, 37, 391-398.

Khlestkina, E. K., Röder, M. S., Pshenichnikova, T. A., \& Börner, A. (2010). Functional diversity at the $R c$ (red coleoptile) locus in wheat (Triticum aestivum L.). Molecular Breeding, 25, 125-132.

Krattinger, S. G., Lagudah, E. S., Spielmeyer, W., Singh, R. P., Huerta-Espino, J., McFadden, H., et al. (2009). A putative $\mathrm{ABC}$ transporter confers durable resistance to multiple fungal pathogens in wheat. Science, 323, 13601363.

Lander, E. S., Green, P., Abrahamson, J., Barlow, A., Daly, M. J., Lincoln, S. E., et al. (1987). MAPMAKER: an interactive computer package for constructing primary genetic linkage maps of experimental and natural populations. Genomics, 1, 174-181.

Laurie, D. A., \& Bennett, M. D. (1988). The production of haploid wheat plants from wheat $\mathrm{x}$ maize crosses. Theoretical and Applied Genetics, 76, 393-397.

Liu, X. M., Smith, C. M., Gill, B. S., \& Tolmay, V. (2001). Microsatellite markers linked to six Russian wheat aphid resistance genes in wheat. Theoretical and Applied Genetics, 102, 504-510.

Liu, X. M., Smith, C. M., \& Gill, B. S. (2002). Identification of microsatellite markers linked to Russian wheat aphid resistance genes Dn4 and Dn6. Theoretical and Applied Genetics, 104, 1042-1048.

Manly, K. F., Cudmore, R. H., Jr., \& Meer, J. M. (2001). Map Manager QTX, cross-platform software for genetic mapping. Mammalian Genome, 12, 930-932.

McIntosh, R. A., Yamazak, Y., Dubcovsky, J., Rogers, J., Morris, C., Somers, D. J., et al. (2008). Catalogue of Gene Symbols for Wheat. http:/www.grs.nig.ac.jp/wheat/komugi/genes/.
McVey, D. V., \& Leonard, K. J. (1990). Resistance to wheat stem rust in spring spelts. Plant Disease, 74, 966-969.

Pink, D. A. C., \& Law, C. N. (2009). The effect of homoeologous group 7 chromosomes upon adult plant resistance of wheat to yellow rust (Puccinia striiformis). Plant Pathology, 34, 255262.

Plaschke, J., Ganal, M. W., \& Röder, M. S. (1995). Detection of genetic diversity in closely related bread wheat using microsatellite markers. Theoretical and Applied Genetics, 91, 1001-1007.

Pshenichnikova, T. A., Osipova, S. V., Permiakova, M. D., Mitrofanova, T. N., Trufanov, V. A., Lohwasser, U., et al. (2008). Mapping of quantitative trait loci (QTL) associated with activity of disulfide reductase and lipoxygenase in grains of bread wheat Triticum aestivum L. seeds. Russian Journal of Genetics, 44, 654-662.

Raman, R., Milgate, A. W., Imtiaz, M., Tan, M. K., Raman, H., Lisle, C., et al. (2009). Molecular mapping and physical location of major gene conferring seedling resistance to Septoria tritici blotch in wheat. Molecular Breeding, 24, 153-164.

Röder, M. S., Korzun, V., Wendehake, K., Plaschke, J., Tixier, M. H., Leroy, P., et al. (1998). A microsatellite map of wheat. Genetics, 149, 2007-2023.

Simón, M. R., \& Cordo, C. A. (1998). Diallel analysis of the resistance components to Septoria tritici in Triticum aestivum. Plant Breeding, 117, 123-126.

Simón, M. R., Perelló, A. E., Cordo, C. A., Larrán, S., van der Putten, P., \& Struik, P. C. (2005). Association between septoria tritici blotch, plant height, and heading date in wheat. Agronomy Journal, 97, 1037-1278.

Simón, M. R., Worland, C. A., \& Struik, P. C. (2005). Chromosomal location of genes encoding for resistance to septoria tritici blotch (Mycosphaerella graminicola) in substitution lines of wheat. Netherlands Journal of Agricultural Sciences, 53, 113-129.

Simón, M. R., Ayala, F. M., Cordo, C. A., Röder, M. S., \& Börner, A. (2007). The exploitation of wheat (Triticum aestivum)/ Aegilops tauschii introgression lines for the detection of gene(s) determining resistance to septoria tritici blotch (Mycosphaerella graminicola). Euphytica, 154, 249-254.

Singh, P. K., Mergoum, M., Ali, S., Adhikari, T. B., Elias, E. M., \& Hughes, G. R. (2008). Identification of new sources of resistance to tan spot, stagonospora nodorum blotch and septoria tritici blotch of wheat. Crop Science, 46, 2047-2053.

Spielmeyer, W., Singh, R. P., McFadden, H., Wellings, C. R., Huerta-Espino, J., Kong, X., et al. (2008). Fine scale genetic and physical mapping using interstitial deletion mutants of $\operatorname{Lr} 34 / \mathrm{Yr} 18$ : a disease resistance locus effective against multiple pathogens in wheat. Theoretical and Applied Genetics, 116, 481-490.

Van Beuningen, L. T., \& Kohli, M. M. (1990). Deviation from the regression of infection on heading and height as a measure of resistance to septoria tritici blotch in wheat. Plant Disease, 74, 488-493.

Wiwart, M., Perkowski, J., Jackowiak, H., Packa, D., Borusiewicz, A., \& Busko, M. (2004). Response of some cultivars of spring spelt (Triticum spelta) to Fusarium culmorum infection. Die Bodenkultur, 55, 29-36.

Zadoks, J. C., Chang, T. T., \& Konzak, C. F. (1974). A decimal code for the growth stage of cereals. Weed Research, 14, 415-421. 